\title{
COMPARAÇÃo ENTRE HIPOCLORITO DE SÓdIO E ÁCIDO PERACÉtico NA INATIVAÇÃo de E. Coll, Colifagos E C. PERFRINGENS EM ÁGUA COM ELEVADA CONCENTRAÇÃo DE MATÉRIA ORGÂNICA
}

\section{COMPARISON BETWEEN SODIUM HIPOCLORITE AND PERACETIC ACID FOR E. COLI, COLIPHAGES AND C. PERFRINGENS INACTIVATION OF HIGH ORGANIC MATTER CONCENTRATION WATER}

\begin{abstract}
JEANETTE BEBER DE SOUZA
Engenheira Civil pela Universidade Federal de Ouro Preto (UFOP). Mestre e estudante de Doutorado do Departamento de Hidráulica e Saneamento da Escola de Engenharia de São Carlos - Universidade de São Paulo

\section{LUIZ ANTONIo DANIEL}

Engenheiro Civil pela Universidade Federal de Minas Gerais (UFMG). Professor Doutor do Departamento de Hidráulica e Saneamento da Escola de Engenharia de São Carlos - Universidade de São Paulo
\end{abstract}

Recebido: 13/05/04 Aceito: 28/01/05

\section{RESUMO}

Foi realizado estudo comparativo em condiçōes experimentais similares, entre hipoclorito de sódio e ácido peracético na desinfecção de água com elevada concentração de matéria orgânica. $\mathrm{O}$ conteúdo de carbono orgânico dissolvido (COD) variou de 4,652 a $30,13 \mathrm{mgC} / \mathrm{L}$ para a água de estudo bruta e após a desinfecção esses valores variaram de 5,105 a 26,16 mgC/L para os ensaios com cloro e de 15,89 a 32,78 mgC/L para os ensaios com ácido peracético. O desempenho dos dois desinfetantes foi avaliado segundo a inativação de três microrganismos indicadores, Escherichia coli ATCC 11229, colifagos e Clostridium perfringens ATCC 13124 que eram previamente cultivados e inoculados à água no momento do experimento. As concentrações aplicadas de cloro eácido peracético foram de 2,0;3,0; 4,0 e 5,0 mg/L e os tempos de contato de 5, 10, 15 e 20 minutos. Para 3,0 mg/L de cloro aplicado, obteve-se $3 \log$ de inativação de E. coli em 20 minutos de contato, 2,92 log de inativação de fagos em 10 minutos e $2 \log$ de inativação de $C$. perfringens em 15 minutos. Os resultados dos ensaios de desinfecção com ácido peracético indicaram efetiva inativação dos microrganismos indicadores empregados, mesmo na presença de elevada concentração de matéria orgânica. Para $5,0 \mathrm{mg} / \mathrm{L}$ de ácido peracético aplicado e 15 minutos de contato, inativaçôes de E. coli maiores que $6 \mathrm{log}$, de fagos maiores que $5 \log$ em 20 minutos e de $C$. perfringens maiores que $4 \log$ em 10 minutos de contato foram alcançadas.

PALAVRAS-CHAVE: Ácido peracético, cloro, Clostridium perfringens, colifagos, desinfecção de água, Escherichia coli.

\begin{abstract}
The research comparing the action of sodium hypochlorite and peracetic acid to disinfect drinking water with high concentration organic matter was carried out in similar conditions. The dissolved organic carbon (DOC) concentration was from 4.652 to $30.13 \mathrm{mg} / \mathrm{L}$ in raw water, from 5.105 to $26.16 \mathrm{mg} / \mathrm{L}$ in water disinfected with chlorine and from 15.89 to $32.72 \mathrm{mg} / \mathrm{L}$ in water disinfected with peracetic acid. The efficiency of the two disinfectants was evaluated comparing the inactivation of three indicator microorganisms: Escherichia coli ATCC 11229, coliphages and Clostridium perfringens ATCC 13124 previously cultivated and inoculated to the water just before the essay. The Chlorine and peracetic acid concentrations applied was 2.0, 3.0, 4.0 and $5.0 \mathrm{mg} / \mathrm{L}$ each of them with contact time of 5,10,15 and 20 minutes. When applying $3.0 \mathrm{mg} / \mathrm{L}$ of chlorine 3 log inactivation of E. coli with 20 minutes contact time, 2.92 log inactivation of coliphages with 10 minutes contact time and $2 \log$ inactivation of $C$. perfringens with 15 minutes contact time was obtained. The peracetic acid was effective for the inactivation of all indicator microorganisms even to water with high concentration organic matter. Using peracetic acid dosage of $5 \mathrm{mg} / \mathrm{L}$ more than $6 \log$ inactivation of E. coli with 15 minutes contact time, more than 5 log inactivation of coliphages with 20 minutes contact time and more than 4 log inactivation of C. perfringens with 10 minutes contact time was obtained.
\end{abstract}

KEYWORDS: Chlorine, C. perfringens, coliphages, E. coli, peracetic acid, water disinfection.

\section{INTRODUÇÃO}

A desinfecção de águas de abastecimento e esgotos sanitários é condição imprescindível para o controle de doen- ças veiculadas pela água. A cloração, introduzida no início do século XIX objetivando a redução da propagação de doenças pela água, indubitavelmente contribuiu para tal fim.
No entanto, a despeito do uso mundialmente difundido do cloro como principal desinfetante de água de abastecimento, surtos de doenças de veiculação hídrica continuam ocorrendo, não ape- 
nas em países em desenvolvimento, mas também em países industrializados nos quais os padrões de higiene são bastante rigorosos e prescritos por severas regulamentaçóes. Exemplos conhecidos foram os surtos de Cryptosporidium parvum em Milwaukee, Estados Unidos, em 1993, e toxoplasmose em Victoria, Canadá, 1994 (Schoenen, 2002).

Nas últimas décadas, fatores como a intensificação de surtos de doenças relacionadas à presença de patogênicos denominados "emergentes" na água produzida e distribuída à população, produção de toxinas causadas por cianobactérias em mananciais superficiais (Szewzyk et al, 2000) e potencialidade de formação de subprodutos halogenados, quando águas naturais são desinfetadas com cloro, contribuíram para que ocorressem importantes mudanças nos setores de abastecimento de água e saúde pública.

No Brasil, os padrões de potabilidade e os procedimentos relativos ao controle $\mathrm{e}$ vigilância da qualidade da água para consumo humano foram revisados e estabelecidos na Portaria do Ministério da Saúde n ${ }^{\circ}$ 518/2004 (Brasil, 2004).

Nesse contexto, pesquisas sobre processos de desinfecção alternativos ao cloro são promissoras, bem como sobre o emprego de microrganismos indicadores alternativos ou complementares à $E$. coli, no que se refere às dosagens de desinfetante aplicadas, tempos de contato, possibilidade de formação de subprodutos potencialmente perigosos à saúde humana e efetividade de desinfecção em diferentes grupos de microrganismos.

O ácido peracético é um forte desinfetante com largo espectro de atividade antimicrobiana e usado em várias indústrias incluindo a de processamento de alimentos, bebidas, médica, farmacêutica, têxtil, de polpa e de papel. Devido às suas propriedades bactericidas, virucidas, fungicidas e esporicidas, seu uso como desinfetante de esgoto doméstico recebe cada vez mais atenção (Baldry, 1982; Baldry \& French, 1989; Alasri et al, 1992; Sanchez-Ruiz et al, 1995; Gasi et al, 1995; Rajala-Mustonen et al, 1997; Block, 2001). Outras vantagens do ácido peracético como desinfetante de efluentes são: facilidade de implementação de tratamento (sem a necessidade de elevado investimento), largo espectro de atividade mesmo na presença de matéria orgânica heterogênea, ausência de residual ou subprodutos tóxicos e/ou mutagênicos, desnecessária descloração, baixa dependência do $\mathrm{pH}$ e curto tempo de contato.
Em água de abastecimento sua utilização é reportada principalmente como pré-desinfetante para melhoria da qualidade da água bruta, reduzindo a quantidade de patogênicos e, ainda o potencial de formação de subprodutos clorados, quando se usa a cloração como desinfecção final. O cloro deve ser mantido como desinfetante secundário, para manutenção de residual desinfetante.

Este estudo teve por objetivo comparar a resistência relativa dos microrganismos indicadores Escherichia coli ATCC 11229 (indicadora de bactérias), colifagos (indicadores de vírus) e Clostridium perfringens ATCC 13124 (indicador de protozoários) aos desinfetantes hipoclorito de sódio e ácido peracético em água com elevada concentração de matéria orgânica.

\section{MATERIAIS E MÉTODOS}

\section{Água de estudo e condições experimentais}

A água de estudo foi preparada usando água de poço profundo que abastece o Campus I da EESC-USP. A mesma passava por um reator de radiação ultravioleta para eliminação dos microrganismos que porventura estivessem presentes. Os microrganismos indicadores empregados na pesquisa eram previamente cultivados e inoculados à água no momento do experimento.

Para melhor representatividade dos resultados os ensaios de desinfecção foram realizados em duplicata, e os resultados de inativação apresentados constituem a média aritmética dos ensaios. Tanto para a água bruta como para cada par concentração - tempo de contato, previamente definidos, eram coletados dois frascos de igual volume $(100 \mathrm{~mL}) \mathrm{de}$ amostra, para posterior diluição e realização dos exames microbiológicos.

\section{Preparação e quantificação dos microrganismos}

As cepas de bactérias usadas foram E.coli ATCC 11229, C. perfringens ATCC 13124 e E. coli CIP 55.30, como hospedeira dos fagos, adquiridas da Fundação Tropical de Pesquisas e Tecnologia André Tosello, situada em Campinas, SP. Os colifagos foram isolados do efluente de um reator anaeróbio de leito expandido (RALEX) que trata esgoto doméstico, situado no Campus da EESC-USP.

O meio de cultivo para repicagem e conservação da cepa de E. coli foi o Tryptic
Soy Broth (TSB). Para quantificação desses microrganismos empregou-se técnica de filtração em membranas, usando o meio Chromocult Coliform Agar (Merck Cat.No.1.10426). Para quantificação de C. perfringens usou-se técnica de tubos múltiplos, cujo procedimento e meios de cultura estão indicados no método de ensaio CETESB L5.213 (CETESB, 1993). Os meios de cultura usados para isolamento e propagação dos fagos foram o TSB e o TSA (Tryptic Soy Agar) modificado. Os colifagos foram determinados por técnica de contagem de unidades formadoras de placa segundo método de ensaio CETESB L5.225 (CETESB, 1990).

\section{Desinfecção com cloro}

Os ensaios foram realizados em batelada, em 4 béqueres de vidro, de $2 \mathrm{~L}$ de volume, dispostos sobre agitadores magnéticos. Foi preparada solução estoque de cloro em concentração de $1000 \mathrm{mgCl}_{2} / \mathrm{L}$. As dosagens de cloro aplicadas foram de 2,0, 3,0, 4,0 e 5,0 $\mathrm{mgCl}_{2} / \mathrm{L}$ e os tempos de contato $5,10,15$ e 20 minutos. Imediatamente após cada tempo de contato, uma alíquota de $10 \mathrm{~mL}$ era retirada para medição de cloro residual e ao restante da amostra contento cloro, era adicionado tiossulfato de sódio (3\%), na proporção de $0,1 \mathrm{~mL}$ para cada $100 \mathrm{~mL}$ de amostra. O cloro residual total e o livre foram medidos respectivamente pelos reagentes DPD-cloro total AccuVac $®$, Cat.25030-25 e DPD-cloro livre AccuVac®, Cat 25020-25, ambos da HACH.

\section{Desinfecção com ácido peracético}

O procedimento experimental de desinfecção com ácido peracético foi feito em batelada, de maneira análoga aos ensaios com cloro. O produto utilizado foi o PROXITANE 1512, constituído por ácido peracético (mínimo 15\%), peróxido de hidrogênio (mínimo 23\%), ácido acético (máximo 16\%) e veículo estabilizante (100\%). As concentrações de ácido peracético adicionadas foram de 2,0, 3,0, 4,0 e 5,0 mg/L e os tempos de contato foram de 5, 10, 15 e 20 minutos. Para medição das concentraçôes de ácido peracético no preparo da solução estoque de $1000 \mathrm{mg} / \mathrm{L}$ foi utilizado o indicador Analytical Test Strips (Merck, 1.100840001). O residual foi medido usando o Kit Vacu-vials ${ }^{\circledR}$ (CHEMetrics), método colorimétrico de leitura fotométrica. 
Carbono orgânico

dissolvido (COD) e

absorbância UV- 254 nm

No tratamento de água as análises de quantificação da matéria orgânica são importantes, seja na otimização dos processos de tratamento, tendo em vista remoção de cor, eficiência dos processos de coagulação/floculação, além do monitoraramento dos compostos orgânicos precursores da formação de subprodutos da desinfecção.

Foram realizadas as análises de COD e absorbância UV-254 nm com o objetivo de verificar possível interferência da matéria orgânica nos processos de desinfecção, bem como avaliar as modificações ocorridas na matéria orgânica.

Para as análises de COD e absorbância UV-254 $\mathrm{nm}$ amostras de $50 \mathrm{~mL}$ eram filtradas em membranas de nitrato de celulose com poros com diâmetro médio de $0,45 \mu \mathrm{m}$, para remover o material particulado, e posteriormente acidificadas com ácido clorídrico.

O conteúdo de COD, expresso em $\mathrm{mgC/L}$, foi medido em equipamento SHIMADZU 5000 A. Para eliminação do carbono inorgânico todas as amostras eram purgadas com nitrogênio puro por 10 a 15 minutos.

Para a determinação da absorção de luz no comprimento de onda $254 \mathrm{~nm}$, utilizava-se as amostras já filtradas e acidificadas anteriormente. O equipamento empregado foi o espectrofotômetro UV 160 A-SHIMADZU.

\section{RESULTADOS E \\ DISCUSSOOES}

\section{Desinfecção com cloro}

Para as concentrações de cloro aplicadas - 2,0, 3,0, 4,0 e 5,0 mg/L nos progressivos tempos de contato de 5,10 , 15 e 20 minutos - foram quantificados o número final $(\mathrm{N})$ de microrganismos indicadores. $\mathrm{O}$ número inicial $(\mathrm{No})$ de microrganismos adicionados à água foi variável conforme a água de estudo. A partir das fraçōes sobreviventes de E. coli, colifagos e C. perfringens, obtidas experimentalmente, foram construídos os gráficos de inativação $\log \mathrm{N} / \mathrm{N}_{0}$ em função do produto C.t - concentração residual de cloro combinado $(C)$ pelo tempo de contato $(t)$, usando como origem o tempo $\mathrm{t}=0$ - correspondente ao tempo de aplicação do cloro na água (Figuras 1 a 4$)$.

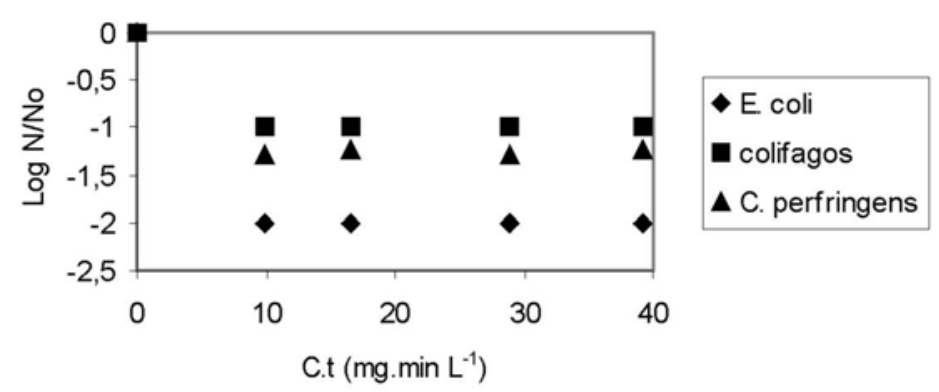

Figura I- Inativação de E. coli, colifagos e C. perfringens para $2,0 \mathrm{mg} / \mathrm{L}$ de cloro aplicado

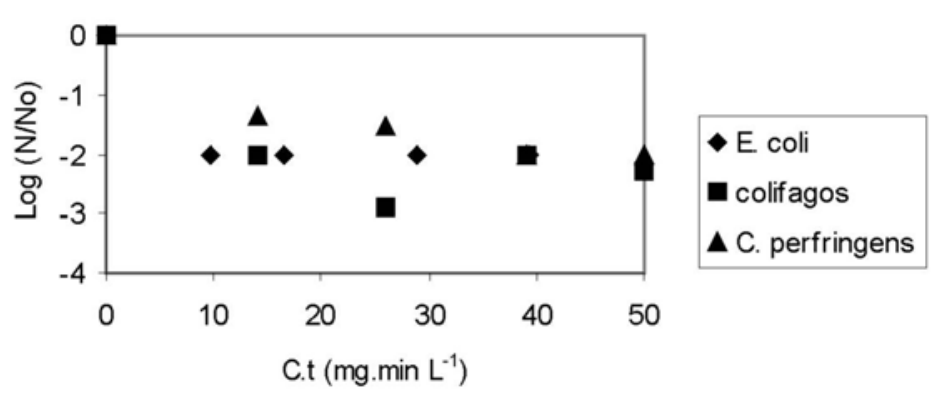

Figura 2- Inativação de E. coli, colifagos e C. perfringens para $3,0 \mathrm{mg} / \mathrm{L}$ de cloro aplicado

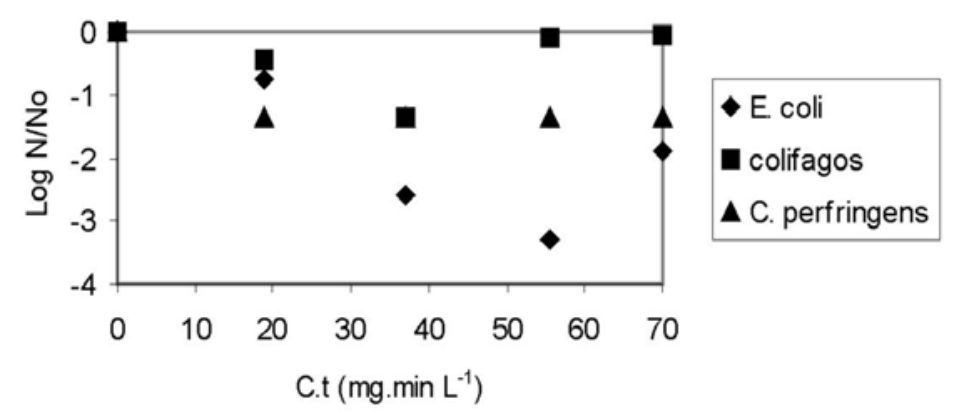

Figura 3- Inativação de E.coli, colifagos e C.perfringens para $4,0 \mathrm{mg} / \mathrm{L}$ de cloro aplicado

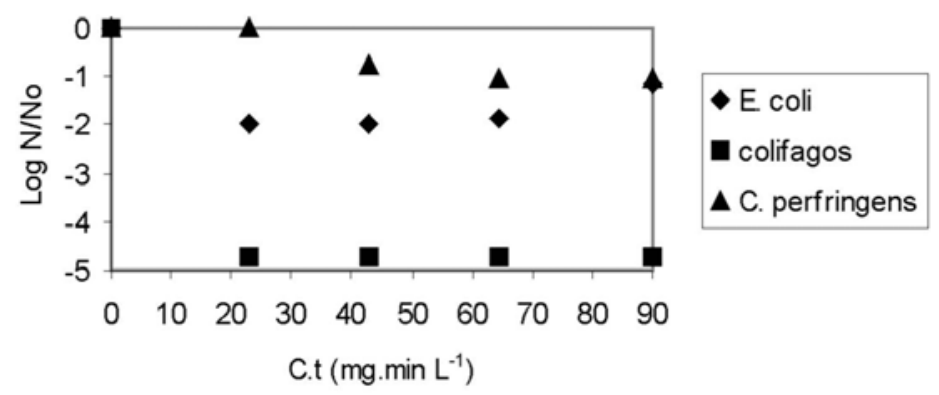

Figura 4- Inativação de E.coli, colifagos e C.perfringens para $5,0 \mathrm{mg} / \mathrm{L}$ de cloro aplicado 
Observou-se grande variabilidade nos resultados de inativação de $E$. coli, colifagos e $C$. perfringens nos ensaios com cloro para as diferentes dosagens e tempos de contato empregados. $\mathrm{O}$ aumento das concentraçóes de cloro aplicadas ao longo dos tempos de contato, não significou necessariamente em melhoria nas eficiências de inativação dos microrganismos indicadores.

Para a concentração de cloro aplicado de 3,0 mg/L obteve-se $3 \mathrm{log}$ de inativação de $E$. coli em 20 minutos de contato, 2,92 log de inativação de colifagos em 10 minutos de contato e $2 \log$ de inativação de $C$. perfringens para os tempos de contato de 15 e 20 minutos. Foram as maiores inativaçôes obtidas para os três microrganismos nas concentrações de cloro e tempos de contato empregados. Ocorreu que maiores concentrações de cloro aplicadas em tempos de contato superiores foram muitas vezes menos eficientes na inativação microbiana.

A grande variabilidade, os desvios nos resultados obtidos, bem como a baixa capacidade de inativação verificadas nos ensaios com cloro foram possivelmente devido à matéria orgânica adicionada à água de estudo e a conseqüente competição entre as reações de oxido-redução e de substituição quando o cloro é aplicado na água.

Foi adicionado em $10 \mathrm{~L}$ de água de poço, $3 \mathrm{~mL}$ de suspensão bacteriana de E.coli em seu meio de cultivo TSB, em concentrações de aproximadamente $10^{6}$ a $10^{7}$ organismos $/ \mathrm{mL}, 3 \mathrm{~mL}$ de suspensão bacteriana de $C$. perfringens em seu correspondente meio DRCM, em concentrações semelhantes $\left(10^{6}\right.$ a $10^{7}$ organismos $/ \mathrm{mL}$ ) e $3 \mathrm{~mL}$ de suspensão de colifagos em meio TSB nas concentraçôes de aproximadamente $10^{5}$ a $10^{6}$ organis$\mathrm{mos} / \mathrm{mL}$, além de quantidades variáveis de solução de substância húmica para a geração de cor.

O rápido e intenso consumo de cloro livre, verificado para a água de estudo em questão, foi atribuído ao material orgânico inerente aos meios de cultura empregados - material rico em nutrientes necessários ao crescimento celular - e adicionados à água como suspensōes de microrganismos, além da substância húmica extraída de solo turfoso.

De fato, verificou-se pequena atividade antimicrobiana do cloro, especificamente nesse estudo, vale ressaltar, e atribuiu-se tal resultado ao comportamento tomado pelo cloro quando adicionado à água com alta concentração de matéria orgânica. Ressalvadas as diferenças inerentes em cada estudo, os resultados obtidos foram comparados com outros sobre cloração de culturas puras.

Shang \& Blatchley (2000) estudaram o destino e a distribuição do cloro em soluçóes aquosas de culturas puras de bactérias. As soluções foram submetidas à cloração em diferentes concentraçôes iniciais de cloro livre. As concentraçóes residuais de cloro foram determinadas pelos métodos de titulação DPD/FAS e espectrometria de massa (MIMS). Curvas de cloração ao breakpoint 'falso-positivas' foram observadas, provavelmente devido à formação de compostos cloroorgânico-nitrogenados. O cloro livre foi observado em quantidades similares pelos dois métodos, DPD/FAS e MIMS, após a demanda ter sido satisfeita pelo material celular das bactérias na solução. Os resultados indicaram a existência de cloramina residual na forma de cloramina orgânica, sendo que esses compostos são geralmente reconhecidos como agentes antimicrobianos pouco efetivos. Além disso, investigaçôes confirmaram que as células das bactérias foram a fonte dos compostos orgânicos contendo nitrogênio. A cinética da cloração de suspensões de culturas puras de bactérias foi também estudada e indicou rápido consumo inicial de cloro livre e posteriormente consumo mais lento, com formação de traços de cloramina inorgânica.

No presente trabalho, foram medidos simultaneamente os residuais de cloro livre e total pelo método DPD colorimétrico. O cloro combinado foi calculado como a diferença entre a concentração de cloro total e cloro livre. No entanto, não foram determinadas quais formas e respectivas concentrações de cloro combinado estavam presentes nas amostras. A leitura de cloro residual livre variou de 0,02 a $0,07 \mathrm{mgCl}_{2} / \mathrm{L}$, denotando rápido consumo do mesmo. A pequena atividade de inativação do cloro observada nesse estudo deveu-se provavelmente à transformação de quase todo o cloro livre aplicado em formas de cloro combinado, que reconhecidamente possuem menor capacidade de inativação de microrganismos.

\section{Desinfecção com ácido peracético}

Com os resultados de inativação dos microrganismos $E$. coli, colifagos e $C$. perfringens obtidos experimentalmente, foram construídos os gráficos $\log \mathrm{N} / \mathrm{N}_{0}$ em função do produto C.t (Figuras 5 a 7). Em que $C$ é a concentração residual de ácido peracético.

Não foi possível a construção dos gráficos de inativação de $E$. coli, colifagos e $C$. perfringens para concentração aplicada de 5,0 mg/L, pois, para a maioria dos resultados obtidos para essa concentração, não foram detectados os microrganismos indicadores.

Os resultados dos ensaios de desinfecção com ácido peracético indicaram efetiva inativação dos microrganismos indicadores empregados, mesmo na presença de elevada concentração de matéria orgânica.

Para a menor concentração de ácido peracético aplicada - 2,0 mg/L - obtevese 5,30 log de inativação de $E$. coli para os tempos de contato de 15 e 20 minutos, sendo que para os mesmos tempos de contato e concentração aplicada de $5,0 \mathrm{mg} / \mathrm{L}$ inativaçóes de $E$. coli maiores que $6 \log$ foram atingidas.

Os indicadores virais, colifagos, foram menos eficientemente inativados pelo ácido peracético que as bactérias $E$. coli. Para 2,0 mg/L e 5 minutos de contato, apenas 0,64 log de inativação foi obtida, sendo que para a mesma concentração e tempo de contato de 20 minutos, 2,60 log de inativação foi obtida para esses indicadores. No entanto, para $5 \mathrm{mg} / \mathrm{L}$ de ácido peracético aplicado e 15 minutos de contato 3,69 log de inativação foi alcançada e para 20 minutos de contato, inativação maior que $5 \log$ foi obtida.

C. perfringens foi mais resistente à desinfecção do que os outros indicadores usados. Para 2,0 mg/L de ácido peracético aplicado e 5 minutos de contato, obtevese $0,34 \log$ de inativação e para $5,0 \mathrm{mg} / \mathrm{L}$ e 5 minutos de contato, 2,21 log de inativação foi alcançada. No entanto, para essa mesma concentração e tempos de contato de 10, 15 e 20 minutos o número final de C.perfringens foi menor que 1 organismo/100 mL, denotando inativaçôes maiores que $4 \mathrm{log}$.

Baldry \& French (1989) obtiveram que $25 \mathrm{mg} / \mathrm{L}$ de ácido peracético rapidamente inativou $E$. coli e $S$. faecalis resultando em inativações do número de bactérias maiores que $10^{5}(99,999 \%)$ em 5 minutos de tempo de contato. Mesmo na presença de grande quantidade de matéria orgânica (meio de cultura), $100 \mathrm{mg} / \mathrm{L}$ de ácido peracético foi requerido para alcançar 5 log de inativação das bactérias. As concentrações efetivas de ácido peracético contra os bacteriófagos 


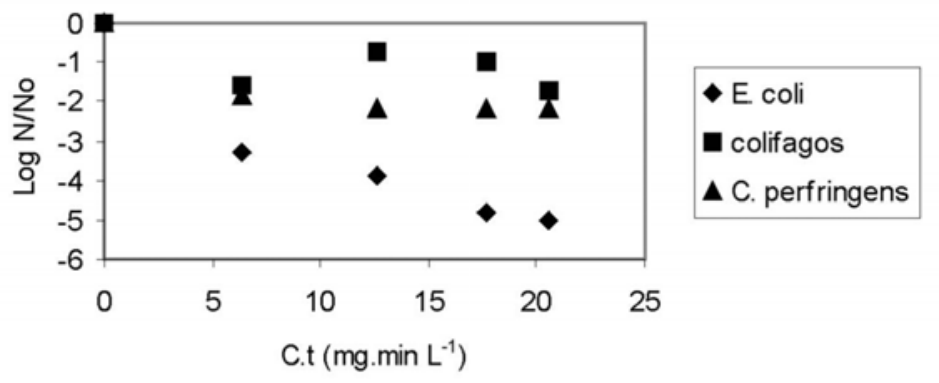

Figura 5 - Inativação de E.coli, colifagos e C.perfringens para 2,0 $\mathrm{mg} / \mathrm{L}$ de ácido peracético aplicado

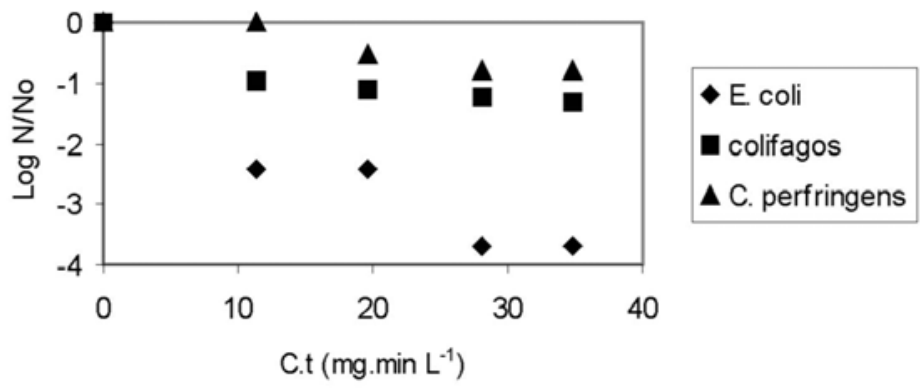

Figura 6 - Inativação de E.coli, colifagos e C.perfringens para $3,0 \mathrm{mg} / \mathrm{L}$ de ácido peracético aplicado

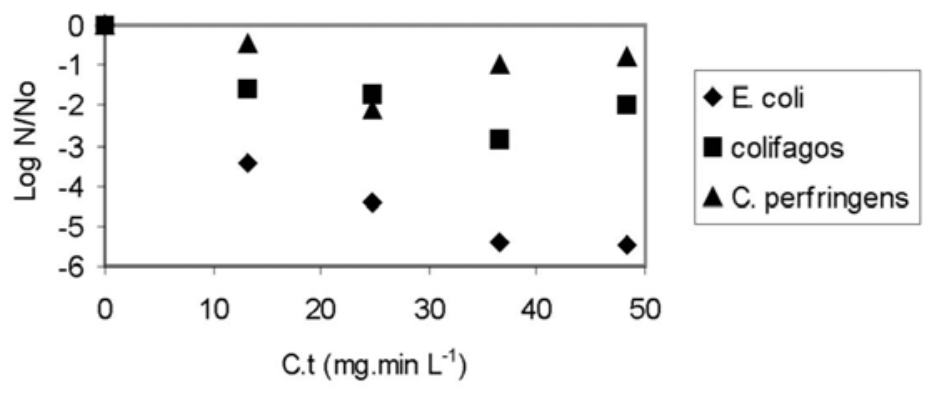

Figura 7 - Inativação de E.coli, colifagos e C.perfringens para $4,0 \mathrm{mg} / \mathrm{L}$ de ácido peracético aplicado

MS2 e $\Phi \times 174$ em água desmineralisada foram de 15 e $30 \mathrm{mg} / \mathrm{L}$ respectivamente, resultando em inativações maiores que $4 \log (99,99 \%)$ em 5 minutos de contato. Na presença de matéria orgânica, aproximadamente $100 \mathrm{mg} / \mathrm{L}$ de ácido peracético foi efetivo na inativação dos bacteriófagos. Concentrações maiores de ácido peracético, 750 a $1500 \mathrm{mg} / \mathrm{L}$ foram requeridas para obtenção de $99,99 \%$ de remoção de Poliovírus em 15 minutos de contato.

Um aspecto relevante apontado por Baldry et al (1991), também observado na presente pesquisa, foi a verificação de que a presença de matéria orgânica na forma de extrato de levedura, afetou negativamente muito mais a eficiência do cloro que a do ácido peracético.
Gasi et al (1995) realizaram estudo de desinfecção de efluentes de lodos ativados com ácido peracético, analisando aspectos relativos à eficiência do processo em relação aos microrganismos: coliformes totais (CT), coliformes fecais (CF), C. perfringens e colifagos. Para inativar 3,7 log de CF foram necessários $5,0 \mathrm{mg} / \mathrm{L}$ de aplicação de ácido peracético e tempo de contato de 27 minutos. As inativaçóes de colifagos observadas para 27 minutos de tempo de contato foram de $94 \%$ e $96 \%$ para dosagens de ácido peracético de 3 e $5 \mathrm{mg} / \mathrm{L}$ respectivamente. Tal fato indica que o produto tem menor poder virucida que bactericida. Observouse, ainda, pequena redução da densidade de $C$. perfringens, $27 \%$ para dosagem de $3 \mathrm{mg} / \mathrm{L}$ e $62 \%$ para dosagem de $5 \mathrm{mg} / \mathrm{L}$.

\section{Carbono orgânico dissolvido (COD) e absorbância UV 254 nm}

As amostras de água bruta e desinfetada eram filtradas antes das análises de carbono orgânico, assim, entende-se que a melhor denominação para os resultados seja carbono orgânico dissolvido e não total. Os resultados das análises de COD e Abs UV - $254 \mathrm{~nm}$ para os ensaios de desinfecção com cloro e ácido peracético são apresentados nas Tabelas 1 e 2, respectivamente.

Os elevados valores de COD para a água bruta devem-se à matéria orgânica proveniente dos meios de cultura e substância húmica adicionadas à água de estudo. Verificou-se aumento dos parâmetros COD e UV-254 nm, após aplicação dos dois desinfetantes empregados.

O aumento do COD e da absorbância UV-254 nm após desinfecção com ácido peracético, é compreensível, visto que o mesmo decompõe-se em ácido acético que contém carbono em sua composição. Segundo Kitis (2003) essa é a maior desvantagem da desinfecção com ácido peracético - 'o aumento do conteúdo orgânico no efluente, podendo provocar recrescimento microbiano, pois o ácido acético, além de estar na mistura do ácido peracético também é formado após a decomposição do produto'.

O aumento do COD e da absorbância UV-254 nm para os ensaios com cloro foi atribuído às características da matéria orgânica presentes na água de estudo, além da especulação de que a oxidação dos sólidos em suspensão promova diminuição do tamanho das partículas fazendo com que as mesmas passem pelas membranas. Desse modo, o carbono seria mais facilmente detectado pelas análises de COD.

Segundo Ferreira (2001), 'com relação à formação de compostos orgânicos halogenados, subprodutos da desinfecção, os resultados de COT e UV-254 nm devem ser analisados, preferencialmente, de forma conjunta. Isto porque a análise de COT fornece qual a concentração total de carbono contido na amostra, não fazendo distinção com relação à natureza dos compostos orgânicos, bem como qual seu grau de reatividade com os agentes oxidantes e desinfetantes aplicados ao processo de tratamento de água. Embora alguns compostos orgânicos possam ser quantificados na análise de COT, como por exemplo, os alcanos, álcoois, carboidratos e aminoácidos, os mesmos não 
Tabela I - COD e Abs UV-254 nm na água bruta e desinfetada com cloro

\begin{tabular}{|c|c|c|c|c|c|c|c|c|}
\hline \multirow[t]{3}{*}{$\mathrm{T}(\mathrm{min})$} & \multicolumn{2}{|c|}{$\mathrm{Cl}_{2}=2 \mathrm{mg} / \mathrm{L}$} & \multicolumn{2}{|c|}{$\mathrm{Cl}_{2}=3 \mathrm{mg} / \mathrm{L}$} & \multicolumn{2}{|c|}{$\mathrm{Cl}_{2}=4 \mathrm{mg} / \mathrm{L}$} & \multicolumn{2}{|c|}{$\mathrm{Cl}_{2}=5 \mathrm{mg} / \mathrm{L}$} \\
\hline & $\begin{array}{l}\text { COD } \\
(\mathrm{mg} / \mathrm{L})\end{array}$ & $\begin{array}{c}\text { UV } \\
254 \mathrm{~nm}\end{array}$ & $\begin{array}{l}\text { COD } \\
(\mathrm{mg} / \mathrm{L})\end{array}$ & $\begin{array}{c}\text { UV } \\
254 \mathrm{~nm}\end{array}$ & $\begin{array}{l}\text { COD } \\
(\mathrm{mg} / \mathrm{L})\end{array}$ & $\begin{array}{c}\text { UV } \\
254 \mathrm{~nm}\end{array}$ & $\begin{array}{l}\text { COD } \\
(\mathrm{mg} / \mathrm{L})\end{array}$ & $\begin{array}{c}\text { UV } \\
254 \mathrm{~nm}\end{array}$ \\
\hline & $A B=5,632$ & $A B=0,026$ & $\mathrm{AB}=8,186$ & $\mathrm{AB}=0,071$ & $A B=23,66$ & $\mathrm{AB}=0,047$ & $\mathrm{AB}=4,652$ & 0,027 \\
\hline 5 & 10,96 & 0,067 & 5,700 & 0,116 & 25,59 & 0,143 & 7,160 & 0,179 \\
\hline 10 & 11,33 & 0,073 & 9,762 & 0,128 & 25,60 & 0,149 & 5,105 & 0,164 \\
\hline 15 & 9,434 & 0,073 & 6,908 & 0,136 & 26,16 & 0,142 & 6,208 & 0,161 \\
\hline 20 & 10,17 & 0,070 & 11,28 & 0,125 & 26,02 & 0,140 & 6,200 & 0,177 \\
\hline
\end{tabular}

Tabela 2 - COD e Abs UV-254 nm na água bruta e desinfetada com ácido peracético

\begin{tabular}{|c|c|c|c|c|c|c|c|c|}
\hline \multirow[t]{3}{*}{$\mathrm{T}(\min )$} & \multicolumn{2}{|c|}{$\mathrm{APA}=2 \mathrm{mg} / \mathrm{L}$} & \multicolumn{2}{|c|}{$\mathrm{APA}=3 \mathrm{mg} / \mathrm{L}$} & \multicolumn{2}{|c|}{$\mathrm{APA}=4 \mathrm{mg} / \mathrm{L}$} & \multicolumn{2}{|c|}{$\mathrm{APA}=5 \mathrm{mg} / \mathrm{L}$} \\
\hline & $\begin{array}{l}\text { COD } \\
(\mathrm{mg} / \mathrm{L})\end{array}$ & $\begin{array}{c}\text { UV } \\
254 \mathrm{~nm}\end{array}$ & $\begin{array}{l}\text { COD } \\
(\mathrm{mg} / \mathrm{L})\end{array}$ & $\begin{array}{c}\text { UV } \\
254 \mathrm{~nm}\end{array}$ & $\begin{array}{l}\text { COD } \\
(\mathrm{mg} / \mathrm{L})\end{array}$ & $\begin{array}{c}\text { UV } \\
254 \mathrm{~nm}\end{array}$ & $\begin{array}{l}\text { COD } \\
(\mathrm{mg} / \mathrm{L})\end{array}$ & $\begin{array}{c}\text { UV } \\
254 \mathrm{~nm}\end{array}$ \\
\hline & $\mathrm{AB}=30,13$ & $\mathrm{AB}=0,352$ & $\mathrm{AB}=28,68$ & $\mathrm{AB}=0,284$ & $\mathrm{AB}=15,53$ & $\mathrm{AB}=0,208$ & $\mathrm{AB}=14,53$ & 0,190 \\
\hline 5 & 32,08 & 0,406 & 32,05 & 0,381 & 28,63 & 0,305 & 24,03 & 0,260 \\
\hline 10 & 32,97 & 0,405 & 31,76 & 0,382 & 28,67 & 0,291 & 15,89 & 0,225 \\
\hline 15 & 32,28 & 0,414 & 30,47 & 0,429 & 27,19 & 0,293 & 25,24 & 0,266 \\
\hline 20 & 32,78 & 0,400 & 31,15 & 0,378 & 18,76 & 0,298 & 25,28 & 0,258 \\
\hline
\end{tabular}

$\mathrm{AB}=$ água bruta; $\mathrm{APA}=$ ácido peracético

apresentam valores de UV-254 nm pelo fato de não possuírem grupos cromóforos capazes de absorverem radiação ultravioleta'.

Ainda, segundo o mesmo autor, 'como a formação de trihalometanos e ácidos haloacéticos ocorre preferencialmente por meio de reações de oxidação e substituição do cloro com compostos orgânicos que apresentam alto grau de aromaticidade e insaturação que, por sua vez, são capazes de absorverem radiação ultravioleta, determinada água bruta com baixa concentração de COT mas alto valor de UV-254 nm pode apresentar grande potencial de formação de compostos orgânicos subprodutos da desinfecção, ainda que apresente um baixo valor de COT. O inverso também pode ocorrer, ou seja, água com alto valor de COT pode apresentar baixa formação potencial de subprodutos da desinfecção, uma vez que os mesmos sejam de cadeia simples, com baixo grau de aromaticidade, grau de insaturação e densidade de grupos funcionais fenólicos'.

Segundo Singer et al (1999), foi reportado por vários grupos de investigadores que a formação de subprodutos halogenados da desinfecção, resultado da cloração de água de abastecimento, é di- retamente proporcional ao conteúdo de carbono aromático dos constituintes orgânicos. Devido às substâncias húmicas possuírem maior conteúdo de carbono aromático do que substâncias não húmicas, as primeiras são predominantes para a formação de subprodutos. Portanto, o controle dos mesmos está diretamente relacionado com a remoção das substâncias húmicas antes da adição do cloro. A absorbância em comprimento de onda de $254 \mathrm{~nm}$ serve como parâmetro para avaliar o conteúdo de carbono aromático dos constituintes orgânicos.

Chang et al (1998), citando vários autores, comentam que alguns compostos comumente encontrados na água, tais como, lignina, tanino, substâncias húmicas e vários compostos aromáticos, absorvem fortemente a radiação ultravioleta, sendo que existe grande correlação entre absorção UV, conteúdo de carbono orgânico, cor, precursores de trihalometanos e outros subprodutos da desinfecção, sugerindo ainda que o consumo de cloro pode ser razoável indicador da formação de subprodutos. Portanto, a dose de cloro, o tempo de contato, TOC UV$254 \mathrm{~nm}$ devem ter impacto significativo para o desenvolvimento de modelos estatísticos de estimativa de THMs.

\section{CONCLUSÕES}

Para as condições empregadas nessa pesquisa, em que se utilizou água com elevada concentração de matéria orgânica, comparada à água potável, o ácido peracético foi mais efetivo que o hipoclorito de sódio na inativação dos três microrganismos estudados.

Foi verificado que o cloro livre adicionado à água de estudo era rapidamente transformado em formas de cloro combinado, o que resultou em pequena inativação dos microrganismos E. coli, colifagos e C.perfringens.

Nos ensaios de desinfecção com ácido peracético, a presença da matéria orgânica na forma de extrato de levedura (meios de cultura), não interferiu na efetividade de desinfecção, como ocorreu com o cloro.

Verificaram-se elevados valores de COD e UV-254 nm para a água bruta. Após a desinfecção com cloro e ácido peracético os valores desses parâmetros aumentaram. No processo de desinfecção com cloro esse aumento foi atribuído à oxidação da matéria orgânica particulada e subseqüente diminuição do tamanho das partículas, as quais eram mais facilmente detectadas nas análises de COD. 
Nos ensaios de desinfecção com ácido peracético, o aumento nos valores desses parâmetros foi devido à presença de ácido acético (produto da decomposição do ácido peracético) o qual contém carbono orgânico em sua estrutura química.

Dos três microrganismos indicadores empregados $C$. perfringens foi o mais resistente aos dois desinfetantes, seguido pelos colifagos que tiveram resistência intermediária e E. coli que foi o organismo menos resistente.

Os dados obtidos permitem concluir sobre a possibilidade de usar o ácido peracético como agente alternativo de desinfecção.

Recomenda-se, entretanto, ao se tratar de água para consumo humano, avaliar criteriosamente a potencialidade de formação de subprodutos da desinfecção.

\section{REFERÊNCIAS}

ALASRI, A., ROQUES, C., MICHEL, G. Bactericidal properties of peracetic acid and hydrogen peroxide, alone and in combination, and formaldehyde against bacterial water strains. Canadian Journal Microbiological, v.38, p. 635-41, 1992

BALDRY, M.G.C. The bactericidal, fungicidal and sporicidal properties of hydrogen peroxide and peracetic acid. Journal of Applied Bacteriology, v.54, p.417-23, 1982.

BALDRY, M.G.C., et al. Disinfection of sewage effluent whith peracetic acid. Water Science Technology, v.21, n.3, p.203-6, 1989.

BALDRY, M.G.C., FRENCH, M.S. Activity of peracetic acid against sewage indicator organisms. Water Science Technology, v.21, n.6/8, p.1747-9, 1989.
BALDRY, M.G.C., FRENCH, M.S., SLATER, D. The Activity of peracetic acid on sewage indicator bacteria and viruses. Water Science Technology, v. 24, n.2, p.353-357, 1991.

BALDRY, M.G.C., et al. Effluent disinfection in warm climates with peracetic acid. Water Science Technology, v.31, n.5-6, p.161-4, 1995.

BLOCK, S.S. Disinfection, Sterilization and Preservation. 5 ed. Philadelphia, PA: Lippincott Willians \& Wilkins, 1481 p. 2001.

BRASIL - Ministério da Saúde. Portaria $n^{\circ} 518$, de 25 de março de 2004.

CETESB (Companhia de Tecnologia de Saneamento Ambiental). Determinação de colifagos em amostras de água. Método de ensaio L5/225. 24p, São Paulo, Brasil, 1990.

CETESB (Companhia de Tecnologia de Saneamento Ambiental). Clostridium perfringens: determinação em amostras de água pela técnica dos tubos múltiplos. Método de ensaio L5/213. 27p, São Paulo, Brasil, julho, 1993.

CHANG,J.E.E., CHIANG, P.C., LIN, T.F. Development of surrogate contaminant parameters for source water quality standards in Taiwan, ROC. Chemosphere, v.37, n. 4, p. 593-606, 1998.

FERREIRA FILHO, S. S. Remoção de compostos orgânicos precursores de subprodutos da desinfecção e seu impacto na formação de trihalometanos em águas de abastecimento. Engenharia Sanitária e Ambiental, v. 6, n. 1, p.53-60, 2001.

GASI, T.M.T., et al. Aplicação de ácido peracético para desinfecção se efluentes de lodos ativados. IN: $18^{\circ}$ CONGRESSO BRASILEIRO DE ENGENHARIA SANITÁRIA E AMBIENTAL, 18, Salvador. Anais...1995.

KITIS, M.. Disinfection of wastewater with peracetic acid: a review. Environment International. Disponível online www.sciencedirect.com. (2003)

RAJALA-MUSTONEN, R. L., TOIVOLA, P. S., HEINONEN-TANSKI, H. Effects of peracetic acid and UV irradiation on the inactivation of coliphages in wastewater. Water Science Technology, v.35, n.11/12, p.237-41. 1997.

SANCHEZ-RUIZ, C., ROYANO, M. S., MONZÓN, I. T. An evaluation of the efficiency and impact of raw wastewater disinfection with peracetic acid prior to ocean discharge. Water Science Technology , v.32, n.7, p.159-66, 1995.

SCHOENEN, D. Role of disinfection in suppressing the spread of pathogens with drinking water: possibilities and limitations. Water Research, v.36, p.3874-88, 2002.

SHANG, C. BLATCHLEY, E. R. Chlorination of pure bacterial cultures in aqueous solution. Water Research, v. 35, n.1, p. 244-54, 2001.

SINGER, P.C. Humic substances as precursors for potentially harmful disinfection by-products. Water Science Technology, v.40, n.9, p.25-30, 1999.

SZEWZYK, U., et al. Microbiological safety of drinking water. Annu. Rev. Microbiol., v.54, p.81-127, 2000 .

Endereço para correspondência:

Jeanette Beber de Souza

Departamento de Hidráulica e

Saneamento

Escola de Engenharia de São

Carlos

Av. Trabalhador São-carlense, 400

13560-590 São Carlos - SP - Brasil

Tel:(16) 273-9515

Fax: (16) 273-9550

E-mail:jeabeber@sc.usp.br 